three years, it must be remembered that many of the cases found to be diphtheria would be called tonsillitis in the anti-culture days. In 1894 there were 93 cases of scarlet fever with 1 death; in 1895,27 cases with 2 deaths; in 1896,30 cases with 2 deaths; and in 1897, 38 cases with 2 deaths.

To show more fully the alvantages of a careful isolation at the home, or removal to a hospital, I have prepared the following tables to cover the cases of diphtheria and scurlet fever in 1897:

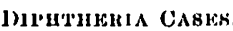

Ssolated at home.

In fanilies with 3 or more other childron, 8 primary cases with infoction of 2 othors.

In familios with 1 or 2 othor ohldren, 12 primary ensey with infoction of 2 others.

In familios with no uthor children, 8 primary chses with no other infections.

Sent to the hospital.

From fomilles with 3 or moro othor childron, 15 primary enses with infection of 8 others.

From famillon with 1 or 2 other childron, 5 pirimary cases with no others infoeted.

1 In 6 of these 8 onses, 3 in ench of 2 families, the infection him shown tisolf boforo the primary c tse was romovod.

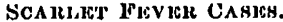

Lolated at home.

In families with 3 or more other childen, 2 primary enses with infoothon of 1 othor.

In fanilieg with 1 or 2 other children, 14 primary enses with infection of "2 others.

In families with no othor children, 3 primary onses with no other infections.

Sent to the hospital.

From famllies with 3 or more othor childron, 5 primary enses with infection of 3 others.

lirom families with 1 or 2 other children, 8 primary onges with infootion of 1 othor.

It will be noticed that there were no cases sent to the hospital from families where there were no other children.

In looking over the tables it should be remembered that cases sent to the hospital are usually from poor families where a doctor is often called in late and the conditions present are most favorable for an early spread of the infection.

In all there were 42 families having a case of diphtheria, and with a total of 102 other children of which only 12 became infected; and there were 32 families having a case of scarlet fever, and with a total of 60 other children of which only 7 became infected.

With the cases enumerated above 1 have not included those occurring at the Massachusetts School for Feeble-minded, which institution is situated on the outskirts of the city. 'That the slight epidemics there have not reached greater proportions, when one considers the nature of the inmates, is undoubtedly due to the intelligent zeal and watchfulness of Dr. W. E. Fermald, the superintendent, and Dr. L. R. Cutler, the visiting physician. 'The disinfecting plant and isolation wards at this institution are well worth a visit from any one interested in health matters.

In cases of typhoid fever, besides endeavoring to trace their cause, the health-officer should make every effort to prevent the cases under observation from becoming sources of infection of milk or water supplies.

I have in this review indicated along what lines work may be best conducted, and have not gone very deeply into the finer details, which will readily suggest themselves to any one. The work here in Waltham which I have begun will be most carefully and skilfully elaborated by my successor, Dr. H. D. Chadwick.

\section{OTinical gDepartment.}

\section{A UNIQUE CASE OF EIDEMA OF TIIE SUPERIOR SURFACE OF 'IHE SOF'T PALA'TE.}

BY 'TIOTIIY J. REARDON, M.D., BOSTON.

'Tus case, presenting, as it does, many interesting features, induced me to study the literature pertaining to it. I was unsuccessful, however, in finding its analogue.

Dr. A., age twenty-eight, has had for the past two years considerable pharyngeal catarrh; he complains especially of dropping in his throat, and of occasional efforts at hawking with expectoration of muco-purulent crusts.

June 20, 1897, just before retiring for the night, he tasted a sawple milk powder; this caused but little discomfort. About 2 o'clock A. M. he was awakened by the sensation of a foreign body in his throat; his throat had a parched feeling also. He went to the mirror, and was surprised at seeing a white tumor dependent from his soft palate, and almost completely filling the isthnus faucium.

He consulted me at my office about 9 A. M., and an examination of the fauces showed a mass the size of a pigeon's egg dependent from the soft palate; its Jongest diameter, which was the horizontal, measured one inch ; its vertical diameter, three quarters of an inch; and it measured the same antero-posteriorly. It was pale, glistening and inseparable from the soft palate. Crepitus was absent. 'The uvula was edematous and the inferior surface of the soft palate was pale. The junction of this surface with the mass was sharply defined and was horizontal instead of convex. No evidence of inflammation was present. Posterior rhinoscopy was reudered impossible by the mass. The patient complained of almost constant deglutatory efforts.

I advised incision of the presenting surface; this was done. A clear serum oozed forth and the mass rapidly diminished in size. Examination of nose and laryux was negative. Urinary analysis was also negative.

At 2 r. s. of the same day the patient returued to my office; the edematous mass had disappeared and it was then possible to explore the vault and posterior nares. The vault was covered with a muco-purulent secretion. On removing this, the recessus medius was seen to be the discharging point and this was treated with a ten-per-cent solution of argentic nitrate; rapid improvement followed.

Etiology. - The presence of suppuration in the recessus wedius suggests the possibility of a crust becoming adherent to the superior surface of the soft palate, and of the edema having been caused by attempts to dislodge the crust. The milk-powder episode I regard as a coincidence.

Differential Diagnosis. - The case is interesting, especially in regard to the possibility of the mass having been due to nasal polypi, which sometimes protrude into the naso-pharynx, but are rarely visible much below the arch of palate. They are also more rounded. Edema of other parts of the palate is, as a rule, inflammatory in origin. A notable exception is the angio-neurotic form, which may appear at any point in the body. Cuntz states that in reference to the palate, it is more frequent at the junction of the hard and soft palate. Polypi dependent from the soft palate 
are rare, and most frequently have their origin at the junction of the soft palate and uvula. A similar condition in appearance wight be induced by an emphysema; such, for example, as follows catherization of the Eustachian tube. A case is reported by Sidlo which was apparently spontaneous in origin, no cause being ascribed; it occupied one-half the palate, and upon being ruptured by the patieut immediately refilled with air.

\section{BIBLIOGRAPHY.}

Sidlo. Wienor med. Presse, 1877, xviii.

Wagner. Krankheitendes woichen Gaumens, v. Ziomsson, Encyc.

Parmentier. Bull. Med. du Nord, Lille, 1868, pp. 350-355.

Cunt\%. Archiv. d. Heil., 1874, xii, p. 63 .

Paget. St. Bartholomew's Hospital Reports, 1886-87.

Schmitt. Krankheiten des Oboren Luftweges, 1895.

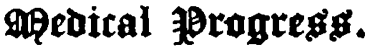

\section{REPORT ON DERMATOLOGY.}

HY JOHN 'T. HOWLN, M.D., BOSTON.

\section{SARCOMATOSIS CUTI8.}

'IANDLER ${ }^{1}$ describes in detail an interesting case of multiple pigmented sarcoma of the skin that was shown by Pick at the meeting of the Association of German Physicians in Prague in March, 1897. 'The subject was a girl of twelve who entered the clinic in October, 1896 , on account of an affection of the fingers that had begun about a year previously. 'There appeared on the dorsal surfaces of both hands small white, exceed. ingly pruritic wheals, which disappeared after a day or two leaving brown spots, which were in their turn intensely pruritic, and which gradually increased in size and became confluent. Six months later these brown spots became infiltrated, until their site was occupied by nodules of the present size. Some of these nodules disappeared from time to time. Nodules also appeared on the elbows. When examined most of the fingers were found to be greatly thickened, especially about the joints, and this thickening to be due to the presence of numerous deep-seated nodules, partly discrete, partly confluent, so as to form large masses of infiltration. Several nodules were present on the elbows, one of which was ulcerated, and the knees also were somewhat affected. There way no eulargement of the lymph glands, and examiuation of the blood rovealed no important changes. 'There was a diminution in the sense of touch on some of the tumors of the fingers, which was regarded, however, as probably due to the tension of the skin. Nodules excised from the left elbow for histological examination showed the picture of a connective-tissue tumor very rich in cells, with spindle cells prodominating - in other words, a spindle-celled sarcoma, of constant structure in all the sections examined, with no degenerative changes in the centre nor pigment formution, as was to be expected from the macroscopic appearances of the tumor. In nodules excised from the right elbow, which were in a state of superficial ulceration, the same appearances were found as in those from the left elbow, with the exception that numerous vessels with proliferating intima were found in the centre, about which there was a profuse collection of cells. 'There was a very great profusion of mastzellen not only in the comnec-

1 Archiv. f. dorm. u. Syph., Bu. xli, Hoft il. tive tissue about the tumor but in the tumor itself. A tumor excised from the finger of the right hand revealed in the sections the presence of two nodules situated close to one unother, lying in the reticulated portion of the corium extending downward to the subcutaneous connective tissue, but not reaching so far upward as the papillary layer. 'This tumor varied from those taken from the elbows in that it was divided into several small portions by connective-tissue bands, poor in cells, with remains of elastic fibres and an occasional blood-vessel. The spaces between these purtitions were filled with closely aggregated spiudle cells, together with some round cells.

The result of the histological examination proved that the tumors belonged to the sarcomata. With regard to the division of the sarcomata in which this case is to be placed, 'Tandler points out that it differs in some important respects from the multiple idiopathic pigmented sarcoma of Kaposi. In this case the nodules were not colored, were not painful on preseure, and on their disappearance left no pigmentation or scarring. It was like tho multiple pigmented sarcoma, however, in the appearance of the tumors first on the hands, in their progression over the forearms, forming larger infiltrations, and in the absence of glaudular enlargements.

Under intramuscular injections of Fowler's solution, one part to three of water, which were given every second or third day in gradually increasing doses, the tumors grew perceptibly smaller in the course of two and a half months. The injections were then omitted and Fowler's solution given internally. When the patient left the hospital the tumors on the fingers had almost entirely disappeared, leaving only a reddishblue color of the skin over their sites and some looseness of the integument. 'The tumors on the forearms and elbows had disappeared entirely. 'The patient's general condition was good.

\section{ALEPPO BOIL.}

Nicolle and Noury-Bey ${ }^{2}$ of Constantinople have studied nine cases of this peculiar affection. 'The disease is of great frequency and the statement has been made that none of the natives escape it, while Europeans are less often affected. It is conmunicable from man to man, and natives of Aleppo have often carried the disease into parts of Asia Minor where it was previously unknown. It occurs at all seasons of the year and does not affect animals. Its ordinary seat is the face and the uncovered parts of the body. It has an incubation, when inoculated, of from one week to two months, and begins in the form of a papule of the size of a large acne nodule which gradually increases up to that of a twenty-centime piece. It is not reddened nor painful, and becomes covered with a crust, beneath which is an ulcerated surface, at about the third or fifth month. It begins to cicatrize at the end of three or four months, leaving a permanent, depressed, characteristic scar. There are never any complications, but. it is annoying from its long duration and disfiguring scars. It is generally single, ulthough sometimes there are from ten to twelve. 'Treatment has proved of no avail, except that of respecting the crusts and making soothing applications.

All the writers who have studied this affection have constantly found micrococci in the lesions, in some cuses staphylococci, in otleers streptococci. Nicolle 2 Annules do l'Institut Pastour, Ootobor, 1807. 